\title{
Development of an artificial fruit prototype for monitoring mango skin and flesh temperatures during storage and transportation
}

\author{
Osvaldo Campelo de Mello Vasconcelos ${ }^{\mathrm{a}}$, Guilherme José Bolzani de Campos Ferreira ${ }^{\mathrm{b}}$, \\ José de Castro Silva ${ }^{\mathrm{c}}$, Barbara Janet Teruel Mederos ${ }^{\mathrm{d}}$, Sérgio Tonetto de Freitas ${ }^{\mathrm{e}, *}$ \\ ${ }^{a}$ Federal Institute of Education, BR 210, Km 103, CEP 68997000, Porto Grande, AP, Brazil \\ ${ }^{\mathrm{b}}$ Federal University of Piuaí, BR 135, Km 3, CEP 64900000, Bom Jesus, PI, Brazil \\ ${ }^{\mathrm{c}}$ Federal University of São Francisco Valley, Av Miguel Silva Souza, 590, CEP 48801765, Juazeiro, BA, Brazil \\ ${ }^{\mathrm{d}}$ University of Campinas, Av. Cândido Randon, 501, Barão Geraldo, CEP 13083875, Campinas, SP, Brazil \\ ${ }^{\mathrm{e}}$ Brazilian Agricultural Research Corporation, Embrapa, BR 428, Km 152, CEP 56302 970, Petrolina, PE, Brazil
}

A R T I C L E I N F O

\section{Keywords:}

Mango

Hydrothermal treatment

Cooling

Technology

\begin{abstract}
A B S T R A C T
Postharvest losses in the mango global market may be as high as $30 \%$, affecting the cost of production, which is passed on to the consumer. Lack of homogeneous air temperature in refrigerated containers, packages, pallets and difficulty of inserting temperature sensors in fruit are issues in addressing losses during transport. This study aimed to develop an artificial fruit with skin and flesh thermal behavior equivalent to those of 'Tommy Atkins' mangoes at different maturity stages, which could be used to monitor fruit temperature during storage, transportation and marketing. The materials used to simulate mango skin were white acrylonitrile butadiene styrene (ABS), crystal ABS, and poly lactic acid with wood powder (PLA Wood). Mango flesh was simulated using three agar concentrations, 5, 10 and 15\%. A temperature sensor was inserted in the middle of each artificial fruit ( $42.5 \mathrm{~mm}$ deep into the agar-gel flesh) and another was inserted under the skin ( $1 \mathrm{~mm}$ deep), both in the center and equatorial region to monitor the fruit thermal behavior. Skin and flesh temperature changes were monitored during refrigerated storage with or without hydrothermal treatment. The thermal behaviors of White ABS and Crystal ABS skins were different from those of the mangoes, and it was not possible to simultaneously obtain high correlation with fruit at different maturity stages. Artificial fruit with PLA Wood skin and flesh containing $15 \%$ agar showed skin and flesh thermal behavior similar to that of mangoes at different maturity stages defined through the quality attributes skin and flesh color, soluble solids, citric acid, $\mathrm{pH}$ and firmness, with $\mathrm{R}^{2}=97 \%$, coefficient of variation between 7 and $17 \%$ and P > F at $99 \%$ confidence level. Artificial fruit with PLA Wood skin and flesh containing $15 \%$ agar can be used for real-time monitoring of skin and flesh temperatures of 'Tommy Atkins' mangoes at different maturity stages after harvest.
\end{abstract}

\section{Introduction}

The world mango production surpasses 26 million tons (FAO, 2017). European and African consumer markets have losses of 13-18 $\%$, whereas in Brazil loses in packing houses reach about 3.9\% per day (Gustavsson et al., 2011; Ribeiro et al., 2014).

Among environmental variables, temperature is the most important to determine fruit postharvest life. To maintain fruit quality and reduce losses, especially during transportation, environmental temperatures must be tight monitored and controlled to ensure proper fruit tissue temperatures during the postharvest supply chain. From the beginning of the cold chain, operations to maintain low fruit temperature include forced-air precooling followed by transportation in refrigerated containers and trucks, and storage in cold rooms prior to commercialization (Teruel, 2008; Do Nascimento Nunes et al., 2014; Olatunji et al., 2017; Defraeye et al., 2017).

Fruit cooling strategies can vary from more efficient, less efficient and inefficient approaches such as forced-air cooling, storage in cold chambers and refrigerated containers, respectively (Thompson, 2004; Ferrua and Singh, 2009; Lukasse et al., 2011; Defraeye et al., 2015b; Ambaw et al., 2016). In all cases, fruit cooling aims to minimize losses, but temperature measurements are taken in the air or on fruit surface and not in fruit tissues (Jedermann et al., 2014; Defraeye et al., 2015a; O'Sullivan et al., 2016; Defraeye et al., 2017; Wu et al., 2018).

\footnotetext{
* Corresponding author.

E-mail addresses: osvaldo.vasconcelos@ifap.edu.br (O.C. de Mello Vasconcelos), guilherme.ferreira@ufpi.edu.br (G.J.B. de Campos Ferreira), castro.silva@univasf.edu.br (J. de Castro Silva), barbara.teruel@feagri.unicamp.br (B.J. Teruel Mederos), sergio.freitas@embrapa.br (S.T. de Freitas).
} 
Temperature sensors send data by radio frequency (RFID) and are used to record the thermal history along the cold chain. Air or fruit surface temperatures exhibit instantaneous variations under ambient cooling conditions. However, fruit flesh temperature shows a thermal lag due to its inertia and fruit physiology does not react as fast as changes in air temperature. In addition, for climacteric fruit, maturity stage can also affect cooling time due to the effect of physico-chemical quality parameters on flesh thermal behavior (Defraeye et al., 2017; Vasconcelos et al., 2019). Our previous study has shown that mango cooling time is strongly affected by physico-chemical quality (Vasconcelos et al., 2019). The cooling time of mango flesh ranged from 110 to $720 \mathrm{~min}$, which could be modeled and predicted by fruit physico-chemical quality. Quality attributes presenting the highest to the lowest influence on fruit cooling time were fruit weight, flesh and skin color, soluble solids, dry matter, fruit diameter, fruit length, flesh thickness and seed thickness (Vasconcelos et al., 2019).

Monitoring fruit skin and flesh temperatures along the cold chain is very difficult because it requires inserting temperature sensors into the fruit, which affects fruit physiology and losses. In addition, data loggers are required to store skin and flesh temperature data. However, skin and flesh temperatures precisely describe fruit thermal behavior, allowing a better control of the ideal temperature conditions along the cold chain. Therefore fruit rather than air temperatures are being measured in several operations by the North American government and organizations that decide on the compliance with any phytosanitary procedure, such as cold protocol during overseas transportation, and commercial forced-air cooling (Hoang et al., 2012; Zou et al., 2014; PPECB, 2016a,b; Berry et al., 2017).

Alterations in fruit physiological behavior due to the insertion and fixation of temperature sensors, as well as due to the use of hydrothermal treatment that is required for pest control by the markets of Europe, USA and Oceania are important problems to consider when monitoring fruit temperature. Indeed, studies have shown that hotwater treatment increases fruit respiration rate, accelerating ripening, senescence, reduction of weight and reduction of flesh firmness. However, these responses depend on maturity stage and genotype (Ponce de León et al., 1997; Yahia and Pedro-Campos, 1999; Jiménez et al., 2009; Osuna-Garcia et al., 2015).

Previous studies have attempted to develop artificial oranges and apples prototypes to monitor fruit tissue temperatures (De Castro et al., 2004, 2005; Vigneault et al., 2006; Tanaka et al., 2012; Soto-Reyes et al., 2015; Defraeye et al., 2017). However, these studies did not consider the effect of fruit physico-chemical quality on fruit thermal behavior. Indeed, variability in mango physico-chemical quality can result in $42.0 \%$ to $73.6 \%$ differences for fruit cooling times (Vasconcelos et al., 2019), suggesting that an ideal artificial fruit for monitoring fruit skin and flesh temperatures along the cold chain should take into account changes in these quality parameters during ripening, as well as the effect of hydrothermal treatment on physicchemical changes that could affect skin and flesh thermal behaviors.

This study aimed to develop an artificial fruit with skin and flesh thermal behavior equivalent to those of 'Tommy Atkins' mangoes at different maturity stages, which could be used to monitor fruit temperature during storage, transportation and marketing.

\section{Material and methods}

This study was carried out at the Postharvest Physiology and Technology Laboratory at Embrapa, Petrolina, PE, Federal University of Piauí, Bom Jesus, PI, and University of Campinas, Campinas, SP, Brazil.

\subsection{Materials for thermal simulation of mango skin}

The materials used to simulate mango skin were printed using a 3D Pro GTMax3D Core A1 printer (GTMax, Americana, Brazil). Each skin was printed in triplicate with average geometry of $122 \mathrm{~mm}$ length, $80 \mathrm{~mm}$ diameter and $1 \mathrm{~mm}$ thickness. Date were obtained from 150 'Tommy Atkins' mangoes. The dimensions were configurated in the program Solidworks 14.0 (DassaultSystemes, USA). The filaments used for mango skin simulation were acrylonitrile butadiene styrene (ABS) in two colors (Crystal ABS and White ABS) (GTMax, Americana, Brazil) and poly lactic acid (PLA) with $5 \%$ wood powder commercially called PLA Wood (3DLab, Betim, Brazil).

\subsection{Software to print the materials}

The materials were printed using SIMPLIFY 3D software (GTMax, Americana, Brazil). Crystal ABS and White ABS were printed using 0.4mm-diameter brass extrusion nozzles, whereas PLA Wood was printed using 0.5-mm-diameter brass extrusion nozzles. Software tools were used to manipulate $\mathrm{ABS}$ printing, informing table temperature of $110^{\circ} \mathrm{C}$ and nozzle temperatures of $240^{\circ} \mathrm{C}$ for the first printing layer and $233^{\circ} \mathrm{C}$ for the subsequent ones. The thickness of each printing layer was $0.15 \mathrm{~mm}$ (Table 1 ). For PLA Wood printing, table temperature was $60^{\circ} \mathrm{C}$ and extrusion nozzle temperature was $215^{\circ} \mathrm{C}$ for all printing layers. The thickness of the printing layer was $0.20 \mathrm{~mm}$ (Table 1). Printing speed was equal to $80 \mathrm{mms}^{-1}$ for Crystal $\mathrm{ABS}$ and White $\mathrm{ABS}$ and to 60 $\mathrm{mms}^{-1}$ for PLA Wood, with average printing time of $4 \mathrm{~h}$. The filament was lubricated only for PLA Wood with addition of synthetic oil (Singer, Cardeal, Brazil) (Table 1).

\subsection{Artificial flesh}

The artificial flesh was introduced into the skins made of the three types of materials. To simulate the flesh, agar concentrations of 5, 10 and $15 \%$ were used with each artificial skin. Previous studies have shown that these agar concentrations have similar thermal behavior to those of fruit flesh (De Castro et al., 2004, 2005; Soto-Reyes et al., 2015; Defraeye et al., 2017). However, studies attempting to simulate mango flesh have never been accomplished before. Therefore, each artificial mango skin was evaluated with three agar concentrations $(5,10$ and $15 \%)$ to simulate the mango flesh.

For the construction of the artificial fruit, the size was defined based on our previous study with 'Tommy Atkins' fruit with average weight of

Table 1

Technical configuration of 3D printer used to print artificial mango skin.

\begin{tabular}{|c|c|c|c|c|c|}
\hline Filament & Nozzle (mm) & Layer thickness (mm) & Top layers & Bottom layers & Outline Shells $^{\mathrm{a}}$ \\
\hline Crystal ABS & 0.4 & 0.15 & 5 & 4 & 3 \\
\hline White ABS & 0.4 & 0.15 & 5 & 4 & 3 \\
\hline PLA Wood & 0.5 & 0.2 & 5 & 4 & 3 \\
\hline Filament & Table temp. $\left({ }^{\circ} \mathrm{C}\right)$ & Nozzle temp. $\left({ }^{\circ} \mathrm{C}\right)$ & Fan (Nozzle) & Speed $(\mathrm{mm} / \mathrm{s})$ & Lubrication \\
\hline Crystal ABS & 110 & 233 & off & 80 & None \\
\hline White ABS & 110 & 233 & off & 80 & None \\
\hline PLA Wood & 60 & 215 & $50 \%$ & 60 & Synthetic oil \\
\hline
\end{tabular}

a Number of printed shells. 


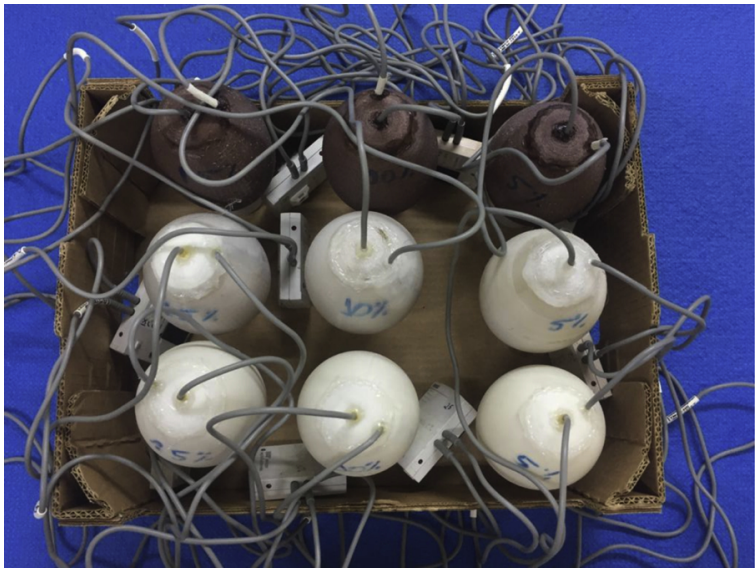

Fig. 1. Artificial fruit with skin of acrylonitrile butadiene styrene (ABS) in two colors (White ABS or Crystal ABS) (bottom or middle rows, respectively) or skin of poly lactic acid (PLA) with 5\% wood powder commercially called PLA Wood (top row) with flesh containing 5, 10 or 15\% of agar (right to left) placed in a cardboard box with dimensions of $38,27,14$, and $0.12 \mathrm{~cm}$ for length, width, height and thickness, respectively.

$513 \mathrm{~g}$, length of $122 \mathrm{~mm}$, and diameter of $80 \mathrm{~mm}$ (Vasconcelos et al., 2019). During the experiment, the artificial fruit were placed in a cardboard box with dimensions of $38,27,14$, and $0.12 \mathrm{~cm}$ for length, width, height and thickness, respectively (Fig. 1).

\subsection{Temperature sensors}

After printing the skin, two type $\mathrm{T}$ copper-constantan thermocouples, TMC 6HD model (Onset, Bourne, USA) were inserted into the artificial fruit (Fig. 1). The surface thermocouple (T Surface) was fixed under the skin $(1 \mathrm{~mm})$ with silicon at half the length of the surface wall at $57 \mathrm{~mm}$, whereas the central thermocouple (T Center) was inserted at the same equatorial distance $(57 \mathrm{~mm})$ and into half the thickness of the agar-gel flesh $(42.5 \mathrm{~mm})$ contained by the skins made of White ABS, Crystal and PLA Wood. Temperature data were collected every minute using both thermocouples in the surface and center of the artificial fruit and then sent to a H12 Hoboware data logger (Onset, Bourne, USA).

\subsection{Thermal behavior of artificial and natural fruit}

The artificial fruit were made of three types of materials to simulate the skin and three agar concentrations to simulate the flesh, and thermocouples were inserted to collect temperature in the center and immediately below the skin. Then, the artificial fruit were subjected to two storage conditions, as described below.

In the first condition, the artificial fruit were initially at room temperature of $25^{\circ} \mathrm{C}$ and then packed in cardboard boxes and subjected to storage at $13^{\circ} \mathrm{C}$. In the second condition, the artificial fruit were subjected to hydrothermal treatment for $80 \mathrm{~min}$ at $46.5^{\circ} \mathrm{C}$ and then packed in cardboard boxes and subjected to storage at $13^{\circ} \mathrm{C}$. All temperature data of the artificial fruit, both in the center ( $\mathrm{T}$ Center) and surface (T Surface), for both conditions, were collected at 1 min intervals and sent to the external data logger (Fig. 1). All thermocouples inserted in the artificial fruit, with or without the hydrothermal treatment, were fixed with silicone to prevent water infiltration under the skin, which could compromise the temperature measurements. In the natural 'Tommy Atkins' fruit, the thermal data collection, hydrothermal treatment and refrigerated storage followed exactly the same protocol used with the artificial fruit (Vasconcelos et al., 2019).

To assess the thermal behavior of the artificial fruit, their thermal data of flesh and skin were compared with thermal data of flesh and skin obtained from a total of 150 'Tommy Atkins' mangoes analyzed at the maturity stages 2, 3 and 4 subjected or not to hydrothermal
Table 2

Physico-chemical quality parameters of 'Tommy Atkins' mangos at different maturity stages.

\begin{tabular}{cccc}
\hline Quality parameter & Maturity 2 & Matutity 3 & Maturity 4 \\
\hline Soluble solids (\%) & $7.0-12.00$ & $12.01-17.00$ & $17.01-22.0$ \\
Citric acid (\%) & $1.55-1.04$ & $1.03-0.52$ & $0.51-0.01$ \\
Skin Lightness & $52.79-38.64$ & $38.63-24.49$ & $24.48-10.33$ \\
Skin chroma & $62.85-52.00$ & $51.99-41.13$ & $41.12-30.26$ \\
Skin hue angle & $116.82-84.17$ & $84.16-51.51$ & $51.50-18.83$ \\
Flesh Lightness & $76.10-62.35$ & $62.34-47.87$ & $47.96-33.58$ \\
Flesh chroma & $85.91-75.63$ & $75.62-65.34$ & $65.33-55.04$ \\
Flesh hue angle & $115.86-104.28$ & $104.27-92.69$ & $92.68-81.1$ \\
pH & $4.8-4.07$ & $4.06-3.34$ & $3.33-2.6$ \\
Flesh firmness (N) & $13.58-9.26$ & $9.25-4.95$ & $4.94-0.61$ \\
\hline
\end{tabular}

treatment followed by refrigerated storage. The determination of fruit maturity stage was accomplished at harvest through measurements of soluble solids, citric acid, skin and flesh color, $\mathrm{pH}$, and flesh firmness (Table 2) (Vasconcelos et al., 2019). Measurements below maturity stage 2 or above maturity stage 4 were considered as fruit at maturity stages 1 or 5, respectively (Santos et al., 2008; Cocozza, 2003).

\subsection{Data analysis}

After skin and flesh temperature data were collected, the cooling times to reached the storage temperature of $13^{\circ} \mathrm{C}$ were compared between artificial fruit and mangoes at different maturity stages. The treatments were arranged in a completely randomized design (CRD) in factorial scheme $(3 \times 3 \times 2)$, corresponding to 3 skins (White ABS, Crystal ABS and PLA Wood), 3 agar concentrations (5, 10 and 15\%) and 2 conditions of initial fruit temperature (with or without hydrothermal treatment). Cooling time data were then used for the statistical analyses.

The program Sigma Plot 12.5 was initially used to compare the cooling times. Normality was assessed by Kolmogorov-Smirnov test. The data were then subjected to analysis of variance and means were compared by Tukey test at $5 \%$. When the data did not meet the normality assumption, one-way analysis of variance on ranks was carried out using the Kruskal-Wallis test. If significant difference was found in this test, a multiple means comparison test (Dunn's Method) was conducted to identify the difference between treatments.

\subsection{Statistical comparison of cooling profile}

After comparison between the cooling times, the cooling profiles were compared between artificial fruit and mangoes at different maturity stages. This comparison aimed to identify the artificial fruit that has thermal behavior of skin and flesh most similar to those of mangoes. To accomplish this comparison, a correlation analysis was carried out between the temperatures of artificial fruit and mangoes. The correlation analysis was conducted using the procedure PROC CORR OUTP = PS (procedure of correlation with output of Pearson). The artificial fruit that showed cooling patterns similar to those of mangoes $(\mathrm{P}<0.05)$ were then subjected to linear regression analysis to confirm the similarity by comparing the values of the variance comparison test $(F)$, probability of significance $(P)$ and determination coefficient $\left(R^{2}\right)$. Regression analysis was conducted using the procedure called PROC REG Model artificial fruit = natural fruit/ NOINT (procedure of regression comparing artificial and natural fruit). Then, the linear regression between the curves of the artificial fruit and natural fruit, both subjected or not to thermal treatment, was calculated.

\section{Results}

The three types of skin (White ABS, Crystal ABS and PLA Wood) showed different thermal behavior for each material. The behaviors of 
Table 3

Correlations between the cooling times for the White ABS skin or flesh of artificial fruit and the cooling time of skin or flesh of 'Tommy Atkins' mangoes at different maturity stages (MAT 2, MAT3, MAT4) subjected or not to hydrothermal treatment.

\begin{tabular}{ccccc}
\hline \multicolumn{5}{c}{ Skin cooling time (minutes) } \\
& $\mathrm{Q}$ & $\begin{array}{c}\text { Difference between } \\
\text { means }\end{array}$ & $\mathrm{H} / \mathrm{F}$ & $\mathrm{P}<0.05$ \\
\hline & & & & \\
\hline Hydrothermal treatment & & 116.5 & 7.0 & Similar \\
White ABS X MAT 2 & 2.91 & 44.4 & 23.1 & Different \\
White ABS X MAT 3 & 2.93 & 38.4 & 23.1 & Similar \\
White ABS X MAT 4 & 2.56 & & & \\
No hydrothermal treatment & & 31.0 & 23.2 & Different \\
White ABS X MAT 2 & 4.45 & 29.8 & 23.2 & Similar \\
White ABS X MAT 3 & 2.47 & 18.6 & 23.2 & Similar \\
White ABS X MAT 4 & 2.79 & & &
\end{tabular}

Flesh cooling time (minutes)

Q Difference between $\quad \mathrm{H} / \mathrm{F} \quad \mathrm{P}<0.05$ means

\begin{tabular}{ccccc}
\hline Hydrothermal treatment & & & & \\
Agar 5 \% X MAT 2 & 1.10 & 16.9 & 23.0 & Different \\
Agar 5 \% X MAT 3 & 2.68 & 41.0 & 23.0 & Different \\
Agar 5 \% X MAT 4 & 1.36 & 20.6 & 23.0 & Different \\
Agar 10 \% X MAT 2 & 1.13 & 17.4 & 23.0 & Different \\
Agar 10 \% X MAT 3 & 2.71 & 41.5 & 23.0 & Similar \\
Agar 10 \% X MAT 4 & 1.39 & 21.1 & 23.0 & Different \\
Agar 15 \% X MAT 2 & 1.39 & 21.4 & 23.0 & Different \\
Agar 15 \% X MAT 3 & 2.98 & 45.5 & 23.0 & Different \\
Agar 15 \% X MAT 4 & 25.1 & 1.6 & 23.0 & Similar \\
No hydrothermal treatment & & & & \\
Agar 5 \% X MAT 2 & 0.02 & 0.03 & 39.6 & Different \\
Agar 5 \% X MAT 3 & 2.69 & 36.3 & 39.6 & Similar \\
Agar 5 \% X MAT 4 & 1.68 & 22.4 & 39.6 & Different \\
Agar 10 \% X MAT 2 & 0.41 & 4.95 & 39.6 & Different \\
Agar 10 \% X MAT 3 & 3.45 & 41.2 & 39.6 & Different \\
Agar 10 \% X MAT 4 & 2.32 & 27.3 & 39.6 & Different \\
Agar 15 \% X MAT 2 & 0.46 & 5.57 & 39.6 & Different \\
Agar 15 \% X MAT 3 & 3.51 & 41.9 & 39.6 & Different \\
Agar 15 \% X MAT 4 & 2.37 & 28.0 & 39.6 & Similar \\
\hline
\end{tabular}

$\mathrm{Q}=$ Quartiles $\mid$ Difference between means = Difference between means of the cooling times of mangoes at different maturity stages and the artificial fruit. $\mid \mathrm{H}$ values by Dunn's Method test (5\%) | F values by Tukey test (5\%) | $\mathrm{P}=$ Probability of significance $\mid$ Similar $=$ similar thermal behavior between artificial and mango fruit at $\mathrm{P}<0.05 \mid$ Different $=$ different thermal behavior between artificial and mango fruit at $\mathrm{P}<0.05$.

White ABS and Crystal ABS skins were very different from those of the mangoes, and correlations with fruit at maturity stages 2, 3 and 4 simultaneously were not satisfactory (Tables 3 and 4).

\subsection{WHITE ABS skin}

The White ABS skin in the artificial fruit was not accurate to simulate the skin of mangoes at the maturity stages 2,3 and 4 . Differences were found in the cooling time at maturity stage 3 with hydrothermal treatment and maturity stage 2 without hydrothermal treatment, compared to the cooling time observed in mangoes (Table 3).

For the thermal behavior of the artificial flesh, agar concentrations of 10 and $15 \%$ were accurate to represent the cooling time observed in mangoes at maturity stages 3 and 4, respectively. In tests with maturity stage 2 , cooling times were not equivalent between the thermal conditions imposed $(\mathrm{P}<0.05)$. Artificial fruit with White ABS skin and flesh containing 5 and 15\% agar concentrations, not subjected to hydrothermal treatment, were accurate to thermally represent mangoes at maturity stages 3 and 4 , respectively (Table 3 ).

Skin made of White ABS and flesh with 5, 10 and 15\% agar
Table 4

Correlations between the cooling times for the Crystal ABS skin or flesh of artificial fruit and the cooling time of skin or flesh of 'Tommy Atkins' mangoes at different maturity stages (MAT 2, MAT3, MAT4) subjected or not to hydrothermal treatment.

\begin{tabular}{ccccc}
\hline \multicolumn{5}{c}{ Skin cooling time (minutes) } \\
& $\mathrm{Q}$ & $\begin{array}{c}\text { Difference between } \\
\text { means }\end{array}$ & $\mathrm{H} / \mathrm{F}$ & $\mathrm{P}<0.05$ \\
\hline & & & & \\
\hline Hydrothermal treatment & 1.74 & 26.50 & 22.77 & Different \\
Crystal ABS X MAT 2 & 2.69 & 40.70 & 22.77 & Similar \\
Crystal ABS X MAT 3 & 2.65 & 39.67 & 22.77 & Similar \\
Crystal ABS X MAT 4 & & & & \\
Without hydrothermal treatment & & 8.65 & 26.69 & Different \\
Crystal ABS X MAT 2 & 0.64 & 28.90 & 26.69 & Similar \\
Crystal ABS X MAT 3 & 2.42 & 27.50 & 26.69 & Similar \\
Crystal ABS X MAT 4 & 2.06 & & & \\
\hline
\end{tabular}

Flesh cooling time (minutes)

Q Difference between $\mathrm{H} / \mathrm{F} \quad \mathrm{P}<0.05$ means

Hydrothermal treatment

Agar $5 \%$ X MAT 2

Agar $5 \%$ X MAT 3

Agar $5 \%$ X MAT 4

Agar $10 \%$ X MAT 2

Agar $10 \%$ X MAT 3

Agar $10 \%$ X MAT 4

Agar $15 \%$ X MAT 2

Agar $15 \%$ X MAT 3

Agar $15 \%$ X MAT 4

Without hydrothermal treatment

Agar $5 \%$ X MAT 2

Agar $5 \%$ X MAT 3

Agar $5 \%$ X MAT 4

Agar $10 \%$ X MAT 2

Agar $10 \%$ X MAT 3

Agar $10 \%$ X MAT 4

Agar $15 \%$ X MAT 2

Agar $15 \%$ X MAT 3

Agar $15 \%$ X MAT 4

1.38
2.97
1.64
1.10
2.68
1.36
1.14
2.73
1.40

0.25
3.28
2.15
0.46
3.13
2.13
0.40
3.42
2.29

$\begin{array}{llc}21.2 & 23.0 & \text { Different } \\ 45.4 & 23.0 & \text { Different } \\ 24.9 & 23.0 & \text { Similar } \\ 16.9 & 23.0 & \text { Different } \\ 41.0 & 23.0 & \text { Different } \\ 20.6 & 23.0 & \text { Different } \\ 17.5 & 23.0 & \text { Different } \\ 41.7 & 23.0 & \text { Similar } \\ 21.2 & 23.0 & \text { Different } \\ & & \\ 3.02 & 39.8 & \text { Different } \\ 39.1 & 39.8 & \text { Different } \\ 25.3 & 39.8 & \text { Different } \\ 6.23 & 39.8 & \text { Different } \\ 42.3 & 39.8 & \text { Different } \\ 28.5 & 39.8 & \text { Similar } \\ 4.77 & 39.8 & \text { Different } \\ 40.9 & 39.8 & \text { Different } \\ 27.0 & 39.8 & \text { Different }\end{array}$

$\mathrm{Q}=$ Quartiles $\mid$ Difference between means = Difference between means for the cooling times of mangoes at different maturity stages and the artificial fruit.| $\mathrm{H}$ values by Dunn's Method test (5\%) | F values by Tukey test (5\%) | $\mathrm{P}=$ Probability of significance. $\mid$ Similar = similar thermal behavior between artificial and mango fruit at $\mathrm{P}<0.05 \mid$ Different $=$ different thermal behavior between artificial and mango fruit at $\mathrm{P}<0.05$.

concentrations have similar thermal behavior compared to mangoes at specific maturity stages. However, low accuracy was observed in the thermal representation of the cooling time of mangoes at maturity stage 2 with all agar concentrations studied. Agar concentration of $15 \%$ was accurate to represent mangoes at maturity stage 4 subjected or not to hydrothermal treatment at $\mathrm{P}<0.05$.

Due to the differences observed in the thermal behavior of the White ABS skin with different agar concentrations to simulate mango skin and flesh, this skin is not appropriate to simulate mangoes at different maturity stages. With White ABS skin, each agar concentration can be used to simulate mango flesh thermal behavior at one maturity stage, but cannot be used to simulate them at the different maturity stages after harvest.

The artificial skin made of Crystal ABS was evaluated under the same conditions imposed to the artificial skin made of White ABS (Table 4).

\subsection{Crystal ABS skin}

Crystal ABS skin was accurate to represent the thermal behavior of 
skin of mangoes at maturity stages 3 and 4, subjected or not to hydrothermal treatment. However, differences were observed for the maturity stage 2, with and without hydrothermal treatment (Table 4).

Artificial fruit with Crystal ABS skin and flesh containing 5 and 15\% agar concentrations, subjected to hydrothermal treatment, showed thermal behavior similar to those of mangoes at maturity stages 4 and 3 , respectively (Table 4). Without hydrothermal treatment, the flesh containing $10 \%$ agar was accurate to represent the flesh of mangoes at the maturity stage $4(P<0.05)$. Artificial fruit with Crystal ABS skin and flesh containing 5, 10 and 15\% agar were not accurate in the thermal simulation of mangoes at maturity stage $2(\mathrm{P}<0.05)$ (Table 4).

In general, White ABS or Crystal ABS skins and the different agar concentrations were representative to simulate mangoes at maturity stages 3 and 4 . The heterogeneity of agar concentrations to thermally represent the flesh of mango fruit at maturity stages 2, 3 and 4 makes it difficult to make a single artificial fruit with these combinations of skin and flesh to represent mangoes at different maturity stages.

\subsection{PLA Wood skin}

The use of PLA Wood to simulate the thermal behavior of the mango skin and flesh with three agar concentrations were precise to represent the fruit in the two, three and four maturity stages submitted or not to the hydrothermal treatment (Table 5).

PLA Wood skin containing different agar concentrations showed the most similar thermal behavior to mangoes. Therefore, linear regression was performed for skin and flesh temperatures between artificial fruit made of PLA Wood skin with $15 \%$ agar flesh and mangoes at maturity stages 2, 3 and 4, subjected or not to thermal treatment (Table 6 and Fig. 2).

PLA Wood skin had similar thermal behavior compared with mango skin at maturity stages 2, 3 and 4 simultaneously. Linear regressions were carried out for the different agar concentrations, correlating them with mango flesh at different maturity stages, subjected or not to hydrothermal treatment (Table 6).

The skin made of PLA Wood and flesh containing 5, 10 and 15\% agar were accurate to represent the thermal behavior of the skin and flesh of mangoes at maturity stages 2,3 and 4, subjected or not to hydrothermal treatment. These combinations of skin and flesh were highly correlated $(97 \%, \mathrm{P}<0.001)$ with the skin and flesh of mangoes (Table 6).

Artificial fruit with PLA Wood skin and flesh containing different agar concentrations were accurate to simulate the thermal behavior of the skin and flesh of mangoes at all maturity stages evaluated. The subsequent evaluations were carried out using only the artificial flesh containing $15 \%$ agar, because it represents the average dry matter content observed in mangoes (Vasconcelos, 2019).

RMSE values from 1.33 to 3.93 were obtained in the analysis of PLA Wood skin and flesh containing $15 \%$ agar to thermally represent 'Tommy Atkins' mangoes. Adjusted R-squared ranged from 0.97 to 0.99 . The coefficients of variation varied from 7.81 to 16.53 and Pr $>\mathrm{F}$ for ratios lower than 0.001 (Table 6).

In the linear regression analysis, it was possible to represent fruit with a single skin material and flesh containing $15 \%$ agar, which were highly correlated with the skin and flesh of mangoes at maturity stages 2, 3 and 4 subjected or not to hydrothermal treatment (Fig. 2).

$\mathrm{R}^{2}$ values from 99.12 to $97.37 \%$ and $\mathrm{P}<0.001$ were obtained in the regression analysis between mangoes at maturity stages 2,3 and 4 and the artificial fruit with PLA Wood skin and flesh containing $15 \%$ of agar, subjected to hydrothermal treatment, in the evaluation of surface and internal temperatures. For the skin and flesh temperatures, in fruit not subjected to hydrothermal treatment, the coefficients ranged from 98.84 to $99.42 \%$ with $\mathrm{P}<0.001$ (Fig. 2).

For the artificial fruit to represent the thermal behavior of mango skin and flesh, both artificial and mango fruit must have the same
Table 5

Correlations between the cooling times for the PLA Wood skin or flesh of artificial fruit and the cooling time of skin or flesh of 'Tommy Atkins' mangoes at different maturity stages (MAT 2, MAT3, MAT4) subjected or not to hydrothermal treatment.

\begin{tabular}{ccccc}
\hline \multicolumn{7}{c}{ Skin cooling time (minutes) } \\
& $\mathrm{Q}$ & $\begin{array}{c}\text { Difference between } \\
\text { means }\end{array}$ & H/F & P $<0.05$ \\
& & & & \\
\hline Hydrothermal treatment & 2.935 & 116.522 & 6.72 & Similar \\
PLA Wood X MAT 2 & 4.045 & 160.208 & 6.72 & Similar \\
PLA Wood X MAT 3 & 3.868 & 151.724 & 6.72 & Similar \\
PLA Wood X MAT 4 & & & & \\
Without hydrothermal treatment & & 0.384 & 26.9 & Similar \\
PLA Wood X MAT 2 & 4.65 & 30.275 & 26.9 & Similar \\
PLA Wood X MAT 3 & 2.503 & 23.75 & 26.9 & Similar \\
PLA Wood X MAT 4 & 1.991 & & & \\
\hline
\end{tabular}

Flesh cooling time (minutes)

Q Difference between $\mathrm{H} / \mathrm{F} \quad \mathrm{P}<0.05$ means

$\begin{array}{ccccc}\text { Hydrothermal treatment } & & & & \\ \text { Agar 5 \% X MAT 2 } & 1.259 & 19.3 & 22.6 & \text { Similar } \\ \text { Agar 5 \% X MAT 3 } & 2.85 & 43.5 & 22.6 & \text { Similar } \\ \text { Agar 5 \% X MAT 4 } & 1.517 & 22.9 & 22.6 & \text { Similar } \\ \text { Agar 10 \% X MAT 2 } & 1.325 & 20.3 & 22.6 & \text { Similar } \\ \text { Agar 10 \% X MAT 3 } & 2.916 & 44.5 & 22.6 & \text { Similar } \\ \text { Agar 10 \% X MAT 4 } & 1.583 & 23.9 & 22.6 & \text { Similar } \\ \text { Agar 15 \% X MAT 2 } & 0.868 & 13.3 & 22.6 & \text { Similar } \\ \text { Agar 15 \% X MAT 3 } & 2.458 & 37.5 & 22.6 & \text { Similar } \\ \text { Agar 15 \% X MAT 4 } & 1.12 & 16.9 & 22.6 & \text { Similar } \\ \text { Without hydrothermal treatment } & & & & \\ \text { Agar 5 \% X MAT 2 } & 0.00827 & 0.1 & 39.4 & \text { Similar } \\ \text { Agar 5 \% X MAT 3 } & 1.747 & 19.8 & 39.4 & \text { Similar } \\ \text { Agar 5 \% X MAT 4 } & 1.895 & 22.6 & 39.4 & \text { Similar } \\ \text { Agar 10 \% X MAT 2 } & 0.384 & 4.6 & 39.4 & \text { Similar } \\ \text { Agar 10 \% X MAT 3 } & 2.164 & 24.6 & 39.4 & \text { Similar } \\ \text { Agar 10 \% X MAT 4 } & 2.294 & 27.3 & 39.4 & \text { Similar } \\ \text { Agar 15 \% X MAT 2 } & 0.374 & 4.5 & 39.4 & \text { Similar } \\ \text { Agar 15 \% X MAT 3 } & 2.153 & 24.508 & 39.4 & \text { Similar } \\ \text { Agar 15 \% X MAT 4 } & 2.283 & 27.229 & 39.4 & \text { Similar }\end{array}$

$\mathrm{Q}=$ Quartiles $\mid$ Difference between means = Difference between means for the cooling times of mangoes at different maturity stages and the artificial fruit.| $\mathrm{H}$ values by Dunn's Method test (5\%) | F values by Tukey test (5\%) | $\mathrm{P}=$ Probability of significance. $\mid$ Similar = similar thermal behavior between artificial and mango fruit at $\mathrm{P}<0.05 \mid$ Different $=$ different thermal behavior between artificial and mango fruit at $\mathrm{P}<0.05$.

temperature profiles during environmental temperature changes. In addition, skin and flesh temperatures changes in the artificial fruit must also represent temperature changes in mango fruit at different maturity stages, which can be used to monitor mango fruit skin and flesh temperatures during fruit ripening after harvest (Fig. 3).

For fruit subjected to hydrothermal treatment, those at maturity stage 2 required longer time to reach the ideal storage temperature of $13^{\circ} \mathrm{C}$ in the center (flesh) and surface (skin). Fruit at maturity stage 3 required $480 \mathrm{~min}$ for the center (flesh) and $200 \mathrm{~min}$ for the surface (skin). The longest time for cooling was observed in mangoes subjected to hydrothermal treatment. Artificial fruit with PLA Wood skin and flesh containing $15 \%$ agar reached coefficients of variation (CV) between 10 and $17 \%$ (Table 6).

For fruit not subjected to hydrothermal treatment, those at maturity stage 2 required a longer time to reach $13{ }^{\circ} \mathrm{C}$ in the center (flesh) and surface (skin). Fruit at maturity stage 3 required $260 \mathrm{~min}$ to reach the storage temperature in the center (flesh) and $180 \mathrm{~min}$ in the surface (skin), and those at maturity stage 4 required 160 to reach the storage temperature in the center (flesh) and $110 \mathrm{~min}$ in the surface (skin) (Fig. 3). The shortest time for cooling occurred in mangoes not 
Table 6

Linear regression analysis between the cooling curves of PLA Wood skin with different agar concentrations and skin or flesh of 'Tommy Atkins' mangoes at different maturity stages (MAT2, MAT3, MAT4).

\begin{tabular}{ccccccc}
\hline \multicolumn{7}{c}{ Skin cooling time (minutes) } \\
& RMSE & R-Square & Adj R-Sq & CV & F \\
\hline & & & & & \\
\hline Hydrothermal treatment & 3.78 & 0.97 & 0.97 & 16.32 & 3535.9 \\
PLA Wood X MAT 2 & 3.10 & 0.98 & 0.98 & 13.37 & 5306.0 \\
PLA Wood X MAT 3 & 2.79 & 0.98 & 0.98 & 12.06 & 6539.3 \\
PLA Wood X MAT 4 & & & & & \\
Without hydrothermal treatment & 1.93 & 0.98 & 0.98 & 10.98 & 3851.7 \\
PLA Wood X MAT 2 & 1.61 & 0.99 & 0.99 & 9.15 & 5565.1 \\
PLA Wood X MAT 3 & 1.84 & 0.98 & 0.98 & 10.47 & 4239.1 \\
PLA Wood X MAT 4 & & & & & & \\
\hline
\end{tabular}

Flesh cooling time (minutes)

\begin{tabular}{cccccc}
\hline & RMSE & R-Square & Adj R-Sq & CV & F \\
\hline Hydrothermal treatment & & & & & \\
Agar 5 \% X MAT 2 & 1.44 & 0.99 & 0.99 & 6.64 & 6401.6 \\
Agar 10 \% X MAT 2 & 2.75 & 0.98 & 0.98 & 12.94 & 6529.2 \\
Agar 15 \% X MAT 2 & 2.71 & 0.98 & 0.98 & 13.18 & 6490.8 \\
Agar 5 \% X MAT 3 & 1.44 & 0.99 & 0.99 & 6.64 & 25632.8 \\
Agar 10 \% X MAT 3 & 1.52 & 0.99 & 0.99 & 7.17 & 21474.9 \\
Agar 15 \% X MAT 3 & 2.16 & 0.99 & 0.99 & 10.50 & 10279.3 \\
Agar 5 \% X MAT 4 & 1.31 & 0.99 & 0.99 & 6.04 & 30983.8 \\
Agar 10 \% X MAT 4 & 1.16 & 0.99 & 0.99 & 5.46 & 37029.5 \\
Agar 15 \% X MAT 4 & 2.78 & 0.98 & 0.98 & 13.53 & 6156.5 \\
Without hydrothermal treatment & & & & & \\
Agar 5 \% X MAT 2 & 2.76 & 0.97 & 0.97 & 17.10 & 1739.6 \\
Agar 10 \% X MAT 2 & 2.90 & 0.97 & 0.97 & 16.92 & 1809.0 \\
Agar 15 \% X MAT 2 & 2.34 & 0.98 & 0.98 & 13.71 & 2746.0 \\
Agar 5 \% X MAT 3 & 1.74 & 0.98 & 0.98 & 10.82 & 4417.2 \\
Agar 10 \% X MAT 3 & 2.29 & 0.98 & 0.98 & 13.32 & 2948.9 \\
Agar 15 \% X MAT 3 & 1.33 & 0.99 & 0.99 & 7.81 & 8569.4 \\
Agar 5 \% X MAT 4 & 2.49 & 0.97 & 0.97 & 15.47 & 2135.5 \\
Agar 10 \% X MAT 4 & 2.84 & 0.97 & 0.97 & 16.53 & 1898.0 \\
Agar 15 \% X MAT 4 & 2.14 & 0.98 & 0.98 & 12.56 & 3280.4 \\
\hline
\end{tabular}

RMSE $=$ Root mean square error $\mid$ R-Square = Coefficient of determination $\mid$ Adj R-Sq = Adjusted R-squared $\mid \mathrm{CV}=$ Coefficient of variation $\mid$ F-Test $=$ test of comparison between variances $\mid \mathrm{Pr}=$ Probability of significance | All linear regressions between the cooling curves of PLA Wood skin with different agar concentrations and skin or flesh of 'Tommy Atkins' mangoes at different maturity stages were statistically significant at values of $\mathrm{P}>\mathrm{F}<0.001$.

subjected to hydrothermal treatment, with coefficients of variation (CV) between 7 and 13\% (Table 6).

\section{Discussion}

\subsection{Thermal simulations of fruit with synthetic materials}

The present study used 5, 10 and $15 \%$ agar concentrations to simulate the dry matter contents previously found in 'Tommy Atkins' mangoes produced in the São Francisco Valley, Petrolina, PE, Brazil (Vasconcelos et al., 2019), as an attempt to simulate the thermal behavior of fruit flesh.

Although previous studies have aimed to simulate fruit thermal behaviors, the approach used were not accurate. These studies have developed polyethylene spheres to simulate the skin and flesh containing plastic ball filled with water, polymer sphere filled with cellulose gel, polymer sphere mixed with 3 and 5\% agar, plastic ball filled with water, and aluminum sphere filled with cellulose gel. However, in these studies the simulations were not able to represent with high accuracy the thermal behavior of the skin and flesh of fruit such as apple and orange (Chuntranuluck et al., 1998; De Castro et al., 2005; Allais et al., 2006; Vigneault et al., 2006; Dehghannya et al., 2012; Delele et al., 2013).
Studies to develop artificial flesh demonstrate that the concentration of specific solutes can affect the thermal behavior of the final product. This information can be used to develop artificial fruit with thermal behavior similar to real fruit. These studies have shown that agar concentrations from 1 to $5 \%$, saccharose up to $5 \%, \mathrm{CaCl}_{2}$ of $0.2 \%$, citric acid from 0 to $10 \%$ and $\mathrm{pH}$ from 0 to 4 affect the thermal behavior of the artificial flesh (De Castro et al., 2004; Birla et al., 2008; SotoReyes et al., 2015). Other simulations have been accomplished using a $3 \%$ agar solution for the flesh and polychlorinated vinyl (PVC) for skin of orange fruit. In these studies, conducted in refrigerated containers, a coefficient of determination of $55.8 \%$ was found for the thermal simulation between artificial fruit and non-climacteric fruit (De Castro et al., 2004, 2005).

Recent studies have accurately conducted fruit thermal simulations. A thermal simulator made for apples had skin composed of a fine plastic layer which simulates the geometry of size, shape and surface texture (Defraeye et al., 2017). Its flesh consisted of water-carbohydrate-air (WCA) compound mixed with gel (Defraeye et al., 2017). Prototype skin and flesh temperatures were measured and the coefficient of determination $\left(R^{2}\right)$ to evaluate the artificial apple fruit reached $95 \%$ significance (Defraeye et al., 2017).

Few studies have been conducted to simulate climacteric fruit due to the wide variations in skin and flesh physical and chemical quality parameters that take place during ripening. The variation of thermal behavior due to fruit physiological alterations makes it difficult to develop a single material for the simulations. For mangoes, the cooling times are different at each maturity stage. In addition, the use of hydrothermal treatment for the export market further hinders the thermal simulation of skin and flesh, due to the physical and chemical alterations in fruit during their ripening (Vasconcelos et al., 2019).

The present study tested several materials to simulate the skin and different agar concentrations to simulate the flesh of 'Tommy Atkins' mangoes. Due to the heterogeneity in the simulations with White ABS and Crystal ABS (Tables 3 and 4), PLA Wood with 15\% agar concentration was chosen because this combination represented with high accuracy the different maturity stages of mangoes subjected or not to thermal treatment, showing high coefficients of determination and low coefficients of variation at $\mathrm{P}<0.001$ (Table 6).

Using a single agar concentration for the flesh and one material for the skin is interesting in terms of feasibility for the large-scale production of artificial fruit, which can be used in packing houses, refrigerated containers and along the entire cold chain. The artificial fruit is a tool to precisely monitor skin and flesh tissue temperatures, which can be used to precisely regulate the temperature in the whole cold chain, reducing mango postharvest losses, as occurs with other fruit (Defraeye et al., 2017).

\subsection{Mango thermal behavior}

Mango fruit at maturity stages two, three and four present distinct cooling times, which may be related to physico-chemical changes during the ripening process after harvest. According to data obtained at the maturity stage 2 , a particular behavior occurs in the central temperature of fruit subjected to hydrothermal treatment. Although difficult to explain, an increase of temperature between $200 \mathrm{~min}$ and $300 \mathrm{~min}$ was observed. However, mangoes at maturity stage 2 resumed temperature reduction until reaching the ideal storage temperature (Fig. 3). The physico-chemical characteristics of mangoes may change when the fruit are subjected to hydrothermal treatment, mainly for less mature fruit. Indeed, studies have demonstrated that harvest followed by hydrothermal treatments can accelerate ripening of different mango cultivars (Jacobi and Giles, 1997; Talcott et al., 2005; Dea et al., 2010). Water loss, respiration rate, flesh firmness, starch degradation, soluble solids content and degradation of pectins can be affected (Joyce et al., 1993), which can influence the thermal behavior and cooling times of the fruit (Vasconcelos et al., 2019). This effect of hydrothermal 


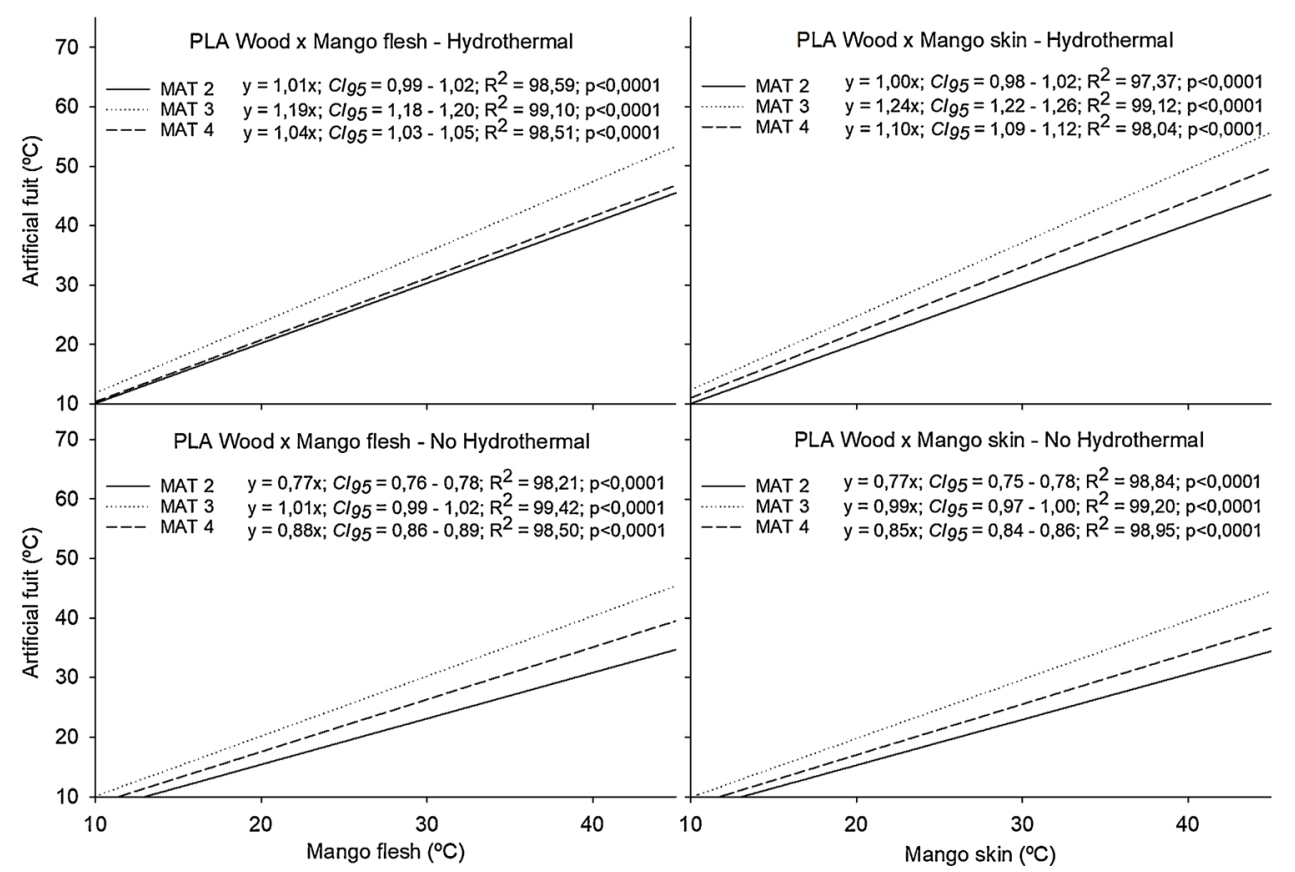

Fig. 2. Linear regression for flesh and skin temperatures between artificial fruit (AF) made of PLA Wood skin with $15 \%$ agar flesh and mangoes at maturity stages 2 , 3 and 4 , subjected or not to thermal treatment.

treatment on physico-chemical changes could help explaining changes in fruit flesh thermal properties observed in mangoes harvested at maturity stage 2 , which were not observed in fruit not subjected to hydrothermal treatment (Fig. 3).

In the simulation of mangoes, shorter cooling times were observed at maturity stages 3 and 4 in fruit subjected to hydrothermal treatment.
These results agree with previous studies showing that hydrothermal treatment can play an important effect on physico-chemical quality parameters, which can directly affect fruit thermal behavior and cooling time (Talcott et al., 2005; Djoua et al., 2009; Dea et al., 2010; Vasconcelos et al., 2019).
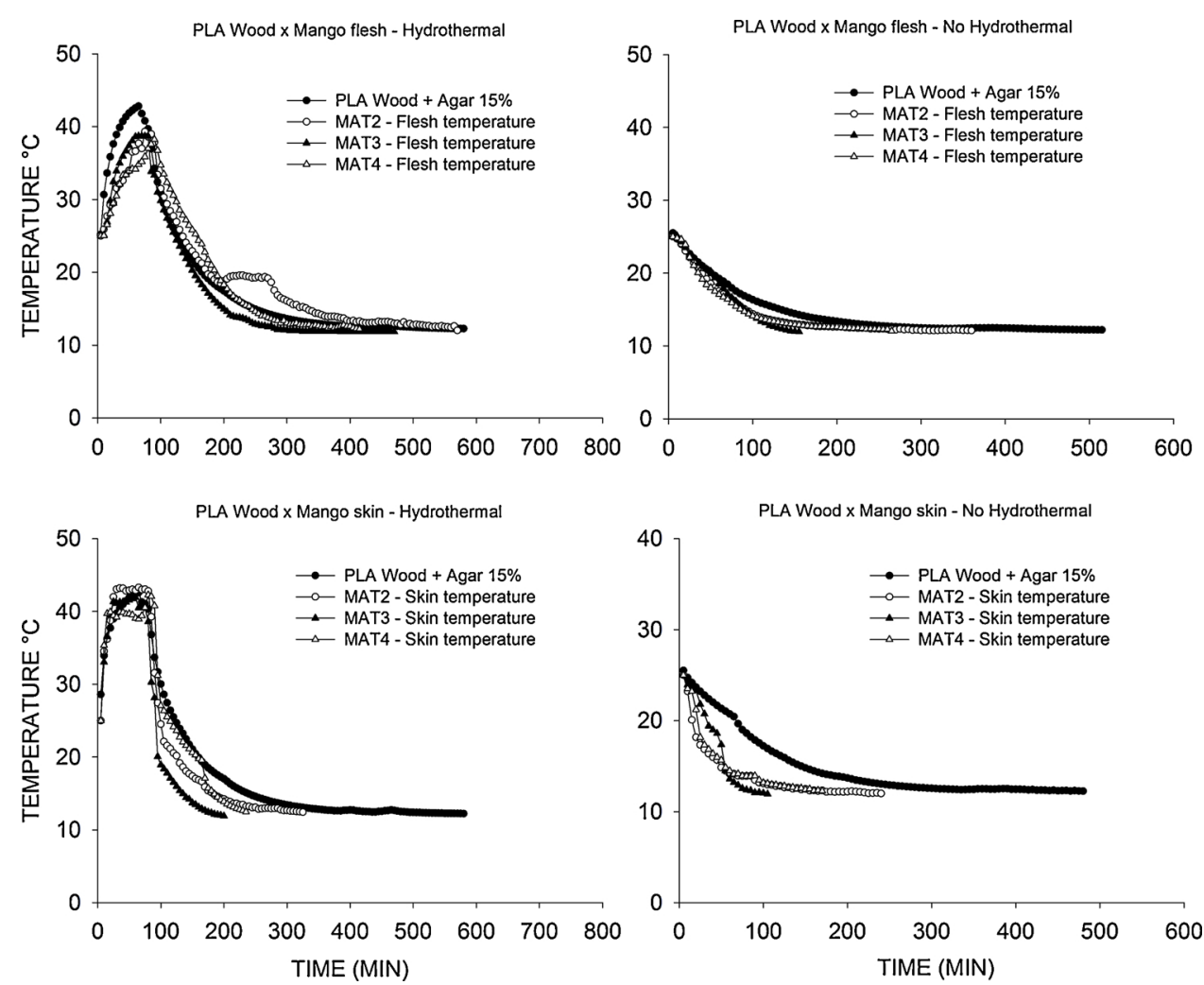

Fig. 3. Thermal analysis of mangoes at maturity stages 2,3 and 4 subjected or not to hydrothermal treatment and artificial fruit with PLA Wood skin and flesh containing $15 \%$ agar. 


\subsection{Applications for the artificial fruit}

Using an artificial fruit with PLA Wood skin and 15\% agar flesh to monitor skin and flesh temperatures in mangoes during storage and transportation can reduce postharvest losses, from harvest to consumers. This tool will allow accurate real-time monitoring of mango skin and flesh temperatures to ensure the offer of high-quality fruit in the market. Artificial fruit can also be used to assist the development of more efficient refrigeration systems to remove heat during storage and transportation, in order to maximize fruit postharvest life. The next step on the development of the artificial mango fruit will be the development of a hardware and software to precisely analyze in real-time skin and flesh temperatures in the fruit, as suggested in other studies (Lukasse et al., 2011; Defraeye et al., 2017).

The cooling patterns and mathematical modeling made it possible to develop the artificial mango fruit and may provide producers with technical information to ensure quality marketing of their products, since the commercial sector usually claims unsatisfactory quality of the product purchased, especially when it is exported. Refrigerated containers and cold rooms in packing houses usually have three thermocouples in straight line to monitor air temperature and relative humidity at a single height, which is not consistent with the homogeneity of air temperature and relative humidity spatialization in the environment. Besides poor distribution of sensors inside the packages, pallet position and height can cause cold injuries or acceleration of ripening (Wu et al., 2018; Defraeye et al., 2016; Dehghannya et al., 2012; Dacanal et al., 2018; Vasconcelos et al., 2017, 2018; Vasconcelos et al., 2019).

The artificial fruit can be used to validate the control of temperature in cold rooms and marine containers. During transportation, the artificial fruit can be placed at inside mango boxes at different heights to monitor real skin and flesh temperatures. It can also be used to evaluate the cooling time of mangoes at different maturity stages in cold rooms to extend the postharvest life of the fruit.

In conclusion, the White ABS and Crystal ABS artificial fruit skins with different agar concentrations to were not able to represent with high accuracy the thermal behavior of 'Tommy Atkins' mangoes at different maturity stages. However, the PLA Wood and the agar concentration of $15 \%$ were able to represent with high accuracy the thermal behavior of the skin and flesh of mangoes, respectively, at the maturity stages 2,3 and 4, subjected or not to hydrothermal treatment.

\section{References}

Allais, I., Alvarez, G., Flick, D., 2006. Modelling cooling kinetics of a stack of spheres during mist chilling. J. Food Eng. 72, 197-209. https://doi.org/10.1016/j.jfoodeng. 2004.11.010.

Ambaw, A., Bessemans, N., Gruyters, W., Gwanpua, S.G., Schenk, A., De Roeck, A., Delele, M.A., Verboven, P., Nicolai, B.M., 2016. Analysis of the spatiotemporal temperature fluctuations inside an apple cool store in response to energy use concerns. Int. J. Refrig. 66, 156-168. https://doi.org/10.1016/j.ijrefrig.2016.02.004.

Berry, T.M., Fadiji, T.S., Defraeye, T., Opara, U.L., 2017. The role of horticultural carton vent hole design on cooling efficiency and compression strength: a multiparameter approach. Postharvest Biol. Technol. 124, 62-74. https://doi.org/10.1016/j. postharvbio.2016.10.005.

Birla, S.L., Wang, S., Tang, J., 2008. Computer simulation of radio frequency heating of model fruit immersed in water. J. Food Eng. 84, 270-280. https://doi.org/10.1016/j. jfoodeng.2007.05.020.

Chuntranuluck, S., Wells, C.M., Cleland, A.C., 1998. Prediction of chilling times of foods in situations where evaporative cooling is significant. Part 3. Appl. J. Food Eng. 37, 143-157. https://doi.org/10.1016/S0260-8774(98)00089-2.

Cocozza, F.D.M., 2003. Maturação e conservação de manga' Tommy Atkins' submetida à aplicação pós-colheita de 1-metilciclopropeno. Tese. Universidade Estadual de Campinas, Campinas, pp. 175

Dacanal, C., Luz, S.N., Turco, S.H.N., Vasconcelos, O.C.M., 2018. Diagnosis and recommendations for the bioclimatic design of grape packing houses in hot and dry climate. Eng. Agríc. 38, 1-6. https://doi.org/10.1590/1809-4430-eng.agric. v38n1p1-6/2018.

De Castro, L.R., Vigneault, C., Cortez, L.A.B., 2004. Container opening design for horti cultural produce cooling efficiency. J. Food Agric. Environ. 2, 135-140.

De Castro, L.R., Vigneault, C., Cortez, L.A.B., 2005. Cooling performance of horticultural produce in containers with peripheral openings. Postharvest Biol. Technol. 38,
254-261. https://doi.org/10.1016/j.postharvbio.2005.07.004.

Dea, S., Brecht, J.K., Nunes, M.C., Baldwinc, A.E., 2010. Quality of fresh-cut 'Kent' mango slices prepared from hot water or non-hot water-treated fruit. Postharvest Biol. Technol. 56, 171-180. https://doi.org/10.1016/j.postharvbio.2010.01.007.

Defraeye, T., Cronjé, P., Berry, T., Opara, U.L., East, A., Hertog, M., Verboven, P., Nicolai, B., 2015a. Towards integrated performance evaluation of future packaging for fresh produce in the cold chain. Trends Food Sci. Technol. 44, 201-225. https://doi.org/ 10.1016/j.tifs.2015.04.008.

Defraeye, T., Nicolai, B., Kirkman, W., Moore, S., Niekerk, S., van Verboven, P., Cronjé, P., 2016. Integral performance evaluation of the fresh-produce cold chain: a case study for ambient loading of citrus in refrigerated containers. Postharvest Biol. Technol. 112, 1-13. https://doi.org/10.1016/j.postharvbio.2015.09.033.

Defraeye, T., Verboven, P., Opara, U.L., Nicolai, B., Cronjé, P., 2015b. Feasibility of ambient loading of citrus fruit into refrigerated containers for cooling during marine transport. Biosyst. Eng. 134, 20-30. https://doi.org/10.1016/j.biosystemseng.2015. 03.012.

Defraeye, T., Wu, W., Prawiranto, K., Fortunato, G., Kemp, S., Hartmann, S., Cronje, P., Verboven, P., Nicolai, B., 2017. Artificial fruit for monitoring the thermal history of horticultural produce in the cold chain. Food Chem. 215, 51-60. https://doi.org/10. 1016/j.jfoodeng.2017.07.012.

Dehghannya, J., Ngadi, M., Vigneault, C., 2012. Transport phenomena modelling during produce cooling for optimal package design: thermal sensitivity analysis. Biosyst. Eng. 111, 315-324. https://doi.org/10.1016/j.biosystemseng.2012.01.001.

Delele, M.A., Ngcobo, M.E.K., Getahun, S.T., Chen, L., Mellmann, J., Opara, U.L., 2013 Studying airflow and heat transfer characteristics of a horticultural produce packaging system using a 3-D CFD model. Part I: model development and validation. Postharvest Biol. Technol. 86, 536-545. https://doi.org/10.1016/j.postharvbio. 2013.08.014.

Djoua, T., Charles, F., Lopez-Lauri, F., Filgueiras, H., Coudret, A., Freire, J.M., DucampCollind, M.N., Sallanona, H., 2009. Improving the storage of minimally processed mangoes (Mangifera indica L.) by hot water treatments. Postharvest Biol. Technol. 52, 221-226. https://doi.org/10.1016/j.postharvbio.2008.10.006.

Do Nascimento Nunes, M.C., Nicometo, M., Emond, J.P., Melis, R.B., Uysal, I., 2014. Improvement in fresh fruit and vegetable logistics quality: berry logistics field studies. Philos. Trans. R. Soc. A Math. Phys. Eng. Sci. 372, 20130307. https://doi.org/ 10.1098/rsta.2013.0307.

FAO, 2017. ORGANIZAÇÃO DAS NAÇÕES UNIDAS PARA A AGRICULTURA E ALIMENTAÇÃO. FAOSTAT. Divisão de estatística. Available at: http://www.fao.org/ faostat/en/\#data/QC. Access: Dec 04, 2018.

Ferrua, M.J., Singh, R.P., 2009. Design guidelines for the forced-air cooling process of strawberries. Int. J. Refrig 32, 1932-1943. https://doi.org/10.1016/j.ijrefrig.2009. 07.011.

Gustavsson, J., Cederberg, C., Sonesson, U., van Otterdijk, R., Meybeck, A., 2011. Global Food Losses and Food Waste: Extend, Causes and Prevention. Rome, Italy, Available at:. pp. 1-24. http://www.madr.ro/docs/ind-alimentara/risipa_alimentara/ presentation_food_waste.pdf.

Hoang, M.H., Laguerre, O., Moureh, J., Flick, D., 2012. Heat transfer modelling in a ventilated cavity loaded with food product: application to a refrigerated vehicle. J. Food Eng. 113, 389-398. https://doi.org/10.1016/j.jfoodeng.2012.06.020.

Jacobi, K.K., Giles, J.E., 1997. Quality of 'Kensington' mango (Mangifera indica Linn.) fruit following combined vapour heat disinfestation and hot water disease control treatments. Postharvest Biol. Technol. 12, 285-292. https://doi.org/10.1016/S09255214(97)00053-7.

Jedermann, R., Nicometo, M., Uysal, I., Lang, W., 2014. Reducing food losses by intelligent food logistics. Philos. Trans. A. Math. Phys. Eng. Sci. 372, 20130302. https://doi.org/10.1098/rsta.2013.0302.

Jiménez, D.P., Taddei, E.B., León, A.G., Robles, J.M.G., Sañudo, R.B., 2009. Efecto del tratamiento hidrotérmico sobre la ultra estructura de la cutıcula del fruto de mango. Rev. Cient. UDO Agríc. 9, 96-102.

Joyce, D.C., Hockings, P.D., Mazucco, R.A., Shorter, A.J., Breeton, I.M., 1993. Heat treatment injury of mango fruit revealed by nondestructive magnetic resonance imaging. Postharvest Biol. Technol. 3, 305-311. https://doi.org/10.1016/09255214(93)90011-Q.

Lukasse, L.J.S., Baerentz, M.B., Kramer-Cuppen, J.E.D., 2011. Quest II: reduction of $\mathrm{CO}_{2}$ emissions of reefer containers. 23rd IIR International Congress of Refrigeration 3203-3210. https://doi.org/10.1016/0925-5214(93)90011-Q.

O'Sullivan, J., Ferrua, M.J., Love, R., Verboven, P., Nicolai, B., East, A., 2016. Modelling the forced-air cooling mechanisms and performance of polylined horticultural produce. Postharvest Biol. Technol. 120, 23-35. https://doi.org/10.1016/j.postharvbio. 2016.05.008.

Olatunji, J.R., Love, R.J., Shim, Y.M., Ferrua, M.J., East, A.R., 2017. Quantifying and visualizing variation in batch operations: a new heterogeneity index. J. Food Eng. 196, 81-93. https://doi.org/10.1016/j.jfoodeng.2016.10.004.

Osuna-Garcia, J.A., Brecht, J.K., Huber, D.J., Nolasco-Gonzalez, Y., 2015. Aqueous 1methylcyclopropene to delay ripening of 'Kent' mango with or without quarantine hot water treatment. HortTechnology 25, 349-357. https://doi.org/10.21273/ horttech.25.3.349.

Ponce de León, L., Muñoz, C., Pérez, L., Diaz de León, F., Kerbel, C., Pérez Flores, L., Esparza, S., Bósquez, E., Trinidad, M., 1997. Hot-water quarantine treatment and water-cooling of 'Haden' mangoes. Acta Hortic. 455, 786-796. https://doi.org/10. 17660/ActaHortic.1997.455.100.

PPECB, 2016a. PPECB Procedural Manual on General Procedure, Loading and Carrying Temperature Requirements for the Export of Perishable Products. HP34C PP04.03e11: Procedure for in Transit Cold Treatment of Specified Quarantine Pest in Citrus Shipped From South Africa. http://refhub.elsevier.com/S0260-8774(17) 30303-5/sref47. 
PPECB, 2016b. PPECB Procedural Manual on General Procedure, Loading and Carrying Temperature Requirements for the Export of Perishable Products. PPO4.02e21F02: Check List for Cold Store and Ambient Loading Facilities Registration. 1-14. http:// refhud.elsevier.com/S0260-8774(17)30303-5/sref48.

Ribeiro, T.P., Lima, M.A.C., de Souza, S.O., Araujo, J.L.P., 2014. Perdas pós-colheita em uva de mesa registradas em casas e embalagem e em mercado distribuidor. Rev. Caatinga 27, 67-74

Santos, D.B., Pereira, M.E.C., Vieira, E.L., Lima, M.A., 2008. Caracterização físico-química dos estádios de maturação da manga' Tommy Atkins' produzida no município de Iaçu-BA. Magistra 20, 342-348.

Soto-Reyes, N., Temis-Pérez, A.L., López-Malo, A., Rojas-Laguna, R., Sosa-Morales, M.E., 2015. Effects of shape and size of agar gels on heating uniformity during pulsed microwave treatment. Food Sci. 80, 1021-1025. https://doi.org/10.1111/17503841.1285 .

Talcott, S.T., Moore, J.P., Lounds-Singleton, A.J., Percival, S.S., 2005. Ripening associated phyto-chemical changes in mangos (Mangifera indica) following thermal quarantine and low-temperature storage. J. Food Sci. 70, 337-341. https://doi.org/10.1111/j. 1365-2621.2005.tb09963.x.

Tanaka, F., Chatani, M., Kawashima, H., Hamanaka, D., Uchino, T., 2012. CFD modeling of infrared thermal treatment of figs (Ficus carica L.). J. Food Process Eng. 35 821-828. https://doi.org/10.1111/j.1745-4530.2010.00630.x.

Teruel, B., 2008. Tecnologias de resfriamento de frutas e hortaliças. Rev. Bras. Agroc. 14, 210-235. https://doi.org/10.18539/cast.v14I2.1904.

Thompson, J.F., 2004. Pre-cooling and storage facilities. In: USDA (Ed.), USDA Agriculture Handbook Number 66: the Commercial Storage of Fruits, Vegetables, and
Florist and Nursery Stocks. USDA, pp. 1-10.

Vasconcelos, O.C.M., Duarte, D., Silva, J.C., Mesa, N.F.O., Mederos, B.J.T., Freitas, S.T. 2019. Modeling 'Tommy Atkins' mango cooling time based on fruit physico-chemical quality. Sci. Hortic. 244, 413-420. https://doi.org/10.1016/j.scienta.2018.09.068.

Vasconcelos, O.C.M., Dacanal, C., Turco, S.H.N., Freitas, S.T., Ramos, C.M.C., Lima,

P.M.L., 2018. Environmental variables in packing houses and their effects on the quality of grapes. Rev. Bras. Eng. Agríc. Amb. 22, 125-130. https://doi.org/10.1590/ 18071929/agriambi.v22n2p125-130.

Vasconcelos, O.C.M., Turco, S.H.N., Dacanal, C., Luz, S.N., Freitas, S.T., 2017. Thermal environment of table grape packing houses in the São Francisco Valley. Eng. Agríc. 37, 35-45. https://doi.org/10.1590/1809-4430-eng.agric.v37n1p35-45/2017.

Vigneault, C., Goyette, B., Castro, L.R., 2006. Maximum slat width for cooling efficiency of horticultural produce in wooden crates. Postharvest Biol. Technol. 40, 308-313. https://doi.org/10.1016/j.postharvbio.2006.01.005.

Wu, W., Haller, P., Cronjé, P., Defraeye, T., 2018. Full-scale experiments in 40-pallet forced-air precoolers for citrus fruit: impact of packaging type and fruit size on cooling rate and heterogeneity. Biosystems Eng. 169, 115-125. https://doi.org/10. 1016/j.biosystemseng.2018.02.003.

Yahia, E.M., Campos, J.P., 1999. The effect of hot water treatment used for insect control on the ripening and quality of mango fruit. Acta Hortic. 509, 495-501. https://doi. org/10.17660/ActaHortic.2000.509.58.

Zou, Z., Chen, Q., Uysal, I., Zheng, L., 2014. Radio frequency identification enabled wireless sensing for intelligent food logistics. Philos. Trans. R. Soc. A. 372, 20130313. https://doi.org/10.1098/rsta.2013.0313. 